\title{
THE REFLECTION OF ENTERPRISE PERFORMANCE THROUGH CASH FLOWS
}

\author{
Professor PhD Petru Ştefea, West University of Timişoara, \\ petru.stefea@upcnet.ro \\ Lecturer PhD Andrei Pelin, West University of Timişoara \\ Teaching Assistent PhD Candidate Daniel Brindescu
}

\begin{abstract}
The meaning diversity of the concept "performance" shows that it is viewed differently by financial information users, according to their perception, and their pursued goals. Thus, managers are focused on the general performance of the enterprise that they are managing, actual and potential investors behold performance through the prism of the achieved investment efficiency, the employees are interested in stability and enterprise development, the creditors appreciate its reliability, and the clients appreciate the quality of commercial relationships as well as company image on the market.

To measure the performance of an enterprise, one must turn not only to its financial results, but also to achieve a global approach on the interdependence between internal and external parameters, quantitative and qualitative, technical and human, physical and financial, ensuring an efficient global management. As a result, the users have to seek the global performance of the company, thus characterizing the company's past, and more importantly, its future. This work, is meant to approach the enterprise performance level, from the perspective of its capacity to create positive financial flows, having in mind that most recent approaches are focused on the reflection of performance in terms of cash.
\end{abstract}

Keywords: performance, financial flows

JEL Codes: G10

\section{The concept of enterprise performance}

In the financial-economic theory and practice, the singular as well as the plural is used, when the problem of performance is approached. Thus, enterprise performance is brought into discussion, however, enterprise economic-financial performances are often analyzed.

We consider that the easiest method of highlighting enterprise performance is through its results, regardless if the results are expressed in absolute measures (profit), or in relative measures (yield).

In the sense of that mentioned above, performance has to be understood as being the behavioral capacity of a system to obtain a result value set at reference levels to define it, comparable with representative achievements from the economic sphere in which this system operates.

We can thus assert, without the risk of being wrong, that the results measure performance, or even define it, when it is set at quotas generally acknowledged as expressing performance.

The expression of results in terms of cash with the aid of financial flows only increases the informational value of result indicators used in measuring the enterprise's financial performance.

The assertion here above starts from the characteristics of liability status, which cause a gap in time between the moment of income recording in bookkeeping and that of their cash in, respectively the moment of expense recording in bookkeeping and that of their payment, gap which may determine the enterprise's financial outcome. In this context, theoreticians and practitioners have focused on the concept of financial flows or treasury flows. 
We consider that the main bonds of financial flows within the analysis of enterprise performances are found at the level of the following criteria:

- the company's financial balance;

- the company's payment capacity;

- the company's financial results.

Enterprise treasury - means of performance status characterization. The enterprise treasury is rather a resultant of enterprise financial flows characterizing the existence or non existence of balance between needs and financial sources, implicitly between income and payments. This state of balance, characterized by a positive level of the net treasury, represents an essential background for the insurance of the enterprise's global performance.

In the American point of view (FAS 95) the treasury is considered to include the solvencies and quasi-solvencies, in the end being short time financial investments, highly solvent, immediately achievable, with a maturity of maximum 90 days.

The British FRS 1 norm, inspired from America, considers that the treasury includes the enterprise' s current cash and bank account availabilities, as well as loans with a maturity lower than 3 months. Shot term investments are included in the treasury, if they are easily convertible in availabilities at the level of known values, if they have sufficiently appropriate maturity to avoid any risk of value variation, and are considered solvency equivalents by other companies.

In the IAS 7 "The cash flow status", although the treasury is not clearly defined, is said to include cash and cash equivalents. The cash includes currency availabilities and deposits on demand. The cash equivalents are short time financial investments and highly solvable, which are easily convertible to known. The cash equivalents are short term investments, highly solvable and easily convertible into known cash amounts, whose risk of changing is insignificant.

Specialists within the economic sphere warn that the concept of "treasury" must not be mistaken, as in the current language, with that of availabilities; the treasury is that which remains from stable resources after financing immobilizations and the need for financing linked to the current activity or the need for circulation funds.

The failure to synchronize incomes with payments results in positive or negative treasury record. Positive treasury signifies a currency surplus at the enterprise's disposal which can be invested on the capital market. Negative treasury however, expresses a global financial imbalance and signifies a currency shortage, covered by short term financing, often at high costs.

An efficient treasury management is that through which the enterprise has its payment capacity ensured. Thus, a prevision of income and payment flows is imposed, meant to "contribute to financial security and enterprise yield, by reducing financial expenses".

On the other hand, in a continuously ascending economy and in the conditions of an ever more various information demand, historical information is insufficient, and enterprises have to forecast in order to survive. The treasury budget is the instrument on which grounds, managers are able to make appropriate decisions to prevent eventual instabilities which might affect enterprise solvency and reliability, and at the same time forecast sources for financing, in the conditions of the existence of a financing need. Its goal is to ensure the balance between enterprise incomes and payments, so that its payment capacity is permanently ensured. Not reaching the goal generates changes within the budget set (sales, production, supplying, investments, general expenses), because the treasury budget encompasses information from several budgets and reunites all income and payment flows.

\section{Financing chart}

The financing chart is presented under the form of a fund flow situation recorded at the level of management period.

The fund flows are being regarded as user, or financing sources variations: 
- user increase or decrease;

- increase or decrease of financing sources.

The financing chart allows for the explanation of net treasury variation at the level of targeted period, on the grounds of the decisions taken in the financing process: the mobilization of financial sources of different types, respectively their use (allocation).

In essence, source mobilization is reflected through the increase of liabilities or decrease of assets, while the increase of assets or decrease of liabilities correspond to use.

Financing source mobilization and use are treated differently, according to the degree of asset solvency, respectively the degree of liability exigibility. Fund flows (assessed on the basis of balance element variations at period level) distinctly reflect the changes occurred at the level of stable balance elements, as well as of temporary elements.

The main utility of the financing chart is found in the sphere of analysis and enterprise dynamic financial balance programming. It is about ensuring balance within the financing process, essential for the continuation of enterprise activity.

The forecast analysis of the financial balance has to lead to those decisions, rules and procedures which are meant to ensure financial balance at the lowest cost. Because, the negative treasury as well as the positive are financing and utilization costs generators, "zero treasury" represents the most used treasury management policy, and consists in keeping the available asset balance as close to zero as possible, in order to reduce treasury management costs.

A net treasury close to zero reflects a state of global balance in the sense on financing, in which stable and cyclic utilizations are covered out of stable and cyclic sources, without liability treasury contribution.

The value of net treasury may be easily calculated based on the information within the balance. However, the way in which this value is formed represents a much greater interest, generating implications on financing costs as well as on financing process stability and activity continuation.

It is evident that permanent sources ensure a higher financing stability, these remaining at the enterprise's disposal for a longer period (higher than 1 year). Their use is, however, less profitable, because their cost is the highest.

The permanent capital costs is justifiably superior to that of short term financing sources costs:

a) risks taken by capital suppliers are higher

- risks related to inflation;

- interest risks;

- risks related to long term exchange rate fluctuations;

- risk of enterprise payment incapacity.

b) the degree of fund immobilization is higher, flexibility being significantly reduced.

In correspondence, short term financing sources present a lower cost, however, are more unstable, their utilization giving rise to financing risks. More exact, financing from sources with a higher degree of exigibility is marked by the risk of source renewal impossibility, after the final date. As long as the enterprise continuously benefits from commercial credits from suppliers, these credits operate similar to permanent sources, being used for immobilized asset financing. The problems appear when commercial credits cannot be renewed (they cannot be replaced by other credits), conditions in which the enterprise finds itself in a state of financing source deficiency, in relation to its needs.

A net treasury which, in a dynamic way keeps itself at a value close to zero, gives the impression of a general balance. In the background, phenomena with impact on the enterprise's financial performance have occurred. The analysis based on the financing chart allows the reflection of the measures to which the enterprise has turned to, in order to keep this balance, as well as the establishment of appropriate measures for the future: 
a) The increase of activity volume or client, stock or supplier management deterioration has lead to the increase of circulation fund necessity, creating imbalances at the level of current activity. The overpassing of current financing source deficiency has been achieved through permanent source allocation: registered capital increase, long or medium term bank credit, dividend non allocation, immobilized asset sale, etc. Global balance has been kept, with the price of some imbalances between needs and permanent sources as well as needs and current sources.

The needs for exploitation process financing have partially been covered from permanent sources, which ensures an increased stability in financing the exploitation, but attracts superior financing costs, with negative impact on profitability.

From the point of view of payment capacity, an increase of enterprise solvency takes place, on the grounds of a possible asset efficiency sacrifice.

As far as the circulation fund necessity has increased on the grounds of activity volume increase, the problem of sustainability of the actual activity volume is raised. A future activity volume decrease shall create the prerequisites of an inefficient use of mobilized permanent sources. The adoption of prevention measures in this sense has to be done in time, in the context of a reduced flexibility in terms of permanent source.

A sustainable increase of activity volume puts the enterprise in the posture of speculating a scale economy. Increase continuation attracts an important risk, which requires careful management: the inappropriate financing of increase and the enterprise's entrance in a financial deadlock.

As far as circulation fund necessity has increased due to a management efficiency decrease, the impact shall be felt at the level of profitability. If the parameters of the circulation fund necessity management policy present successive fluctuations, an important warning sign occurs regarding the short term payment capacity of the enterprise. If the mentioned parameters stabilize, a reserve is created from the point of view of payment capacity (but also profitability), which might be activated in the future.

b) Aggressive policy in terms of investments, registered capital withdrawals, accelerated medium or long term loan reimbursement, have forced increased pressure on the exploitation financing process. The duration of commercial credit granted to clients has been reduced, additional personnel has been hired and raw matter has been replaced with superior quality substitutes, payments towards suppliers, state and personnel have been delayed. The surplus of financing sources released at the level of exploitation cycle under the form of a circulation fund necessity has been used to finance the permanent source deficiency (related to permanent needs).

It is a situation which presents the potential of minimizing financing costs, under the conditions in which cheaper current sources are mainly used. The increase of turnover speed in terms of stock and claims, ensures in parallel an asset efficiency increase.

However, the financing process in very unstable, in the context in which any failure to rebuild current financing sources after reimbursement leads to enterprise activity discontinuity, followed by payment incapacity. The materialization of this risk gives birth to major negative implications, reported at the enterprise's shareholder wealth maximization goals. 


$$
\begin{array}{|l|l}
\text { Reduced payment incapacity risk } & - \\
& \\
& \\
& \mathrm{FR}=0 \\
& \mathrm{NFR}=0 \\
& \mathrm{Lg}=1 \\
\mathrm{TN}=0
\end{array}
$$

Increased payment incapacity risk

High asset efficiency

\section{High financing stability \\ High financing costs}

\section{Low financing stability \\ Low financing costs}

Fig.no.1

By high asset efficiency, "potential efficiency" is understood. The higher the payment incapacity, the higher its materialization probability, and risk materialization shall generate important implications on effective efficiency. Under these conditions, from the point of view of management, the achievement of shareholder wealth maximization inevitably presumes establishing an optimal ratio between payment incapacity risk and potential efficiency.

\section{Cash Flow Statement}

Cash flows are usually defined as cash ins and cash outs and usually represent the equivalent of net change on the level of its reference period. The cash flow state offers information with respect to:

- The company's capacity of payment;

- Assets and liabilities amendments;

- The Company's financial reports;

A proper evaluation of the company's payment capacity would require and imply a minute planning and analysis of a cash flow diagram designed for the period into discussion .

This would highlight the existence or lack of the necessary available assets to pay all financial liabilities according to the planned maturity. By keeping in evidence and controlling the company's general cash flow state, its business environment and nevertheless, the methods used in substantiating all planned cash flows, one would be given the opportunity to evaluate with more accuracy possible risks usually associated to such estimated cash flows. More precisely, we would be given the opportunity to estimate the risks of not performing or differing the liability statement.

A) If regarded form a managerial perspective, the importance of this particular aspect related to the company's possibilities of payment, would be logically derived from the negative consequences that such situations as non-payment or delay in paying the company's debts may trigger. To be aware of the situations and to foresee possible difficulties paying future liabilities, would mean a new opportunity to plan and adopt the best management method.

If the effects resulted from liabilities payment delay, have no negative consequence on the company's general situation, it would be quite a nonsense to put into practice such measures of improvement. Unfortunately, potential effects of delay in payment may, most of the time, have dangerous consequences. 
Possible consequences of delay in payment are briefly presented in the following.

a) Possible deficiencies occurring in the system of paying the company's personnel may have the following consequences:

- Employees become less motivated and this lack of motivation may have a negative impact on the level of work productivity;

- Indiscipline at the work place which may determine and lead to the well known absenteeism phenomenon and implicitly, an alarming reduction of actual efficiency at work.;

- Strikes which firstly affect the actual working time and indirectly, it may deteriorate the company's professional relationships with other social partners;

- Loss of personnel- loss of qualified and professional employees who may easily find better job offers available on work market.

b) Deficiencies in the system of paying the suppliers of stock type goods or suppliers of services, may result into:

- Loss of discounts, taking into account the fact that to obtain such discounts may represent one of the company's main targets (economically speaking, rapid payment of liabilities with the purpose of capitalizing some discounts, does not always seem to be the best solution);

- Payment of some delay penalties;

- Reduction of the period offered by suppliers for commercial credits, adherent to future agreements;

- Loss of some bonuses, facilities usually provided by suppliers as compensation for previous professional relations (as for instance, free transport, priority in the zone of order acceptance);

- Loss of suppliers.

c) Possible consequences of deficiencies in paying the debts towards banks or other financial institutions:

- penalties payment;

- increment of financial costs;

- warranties' execution;

- difficulties in obtaining future credits.

B) As far as the enterprise suppliers are concerned, it is essential that they know its payment capacity, when taking the decision to grant commercial credits.

At the level of client - company, the decision to purchase raw material by means of commercial credit, would determine asset increase and, at the same time, it may represent a true financing source.

The company's claim towards its suppliers represents one of the cheapest financing sources, which in this case, is quite easily to obtain. Such claims usually transform into assets, namely, in raw material stocks necessary for operational activities, which are in fact, implicit claims resulted from deductible value added tax. Such a financing source is usually regarded as a debt by suppliers, namely, an asset which must obligatory be financed.

This claim support offered by suppliers (more precisely, the possibility of financing the client company by means of commercial credit) involves other costs which may be regarded from different perspectives:

- Implicit costs of the sources used by suppliers for claims financing: claim collection would make possible the reimbursement of some sources which contributed to and were used as financing sources;

- Opportunity costs: claim collection would mean another opportunity to reinvest the financing source into an asset which may, in turn, determine an increased output. 
Delay in paying the liabilities towards the supplier would inevitably lead not only to a considerable financing costs increase, but moreover to an evident deterioration of the payment cycle, with negative effects regarding the company's professional relationships with all its sponsors.

Impossibility of payment usually has a chain effect. The only solution to resort to in such situation, is to form a security buffer in the form of bearing funds.

As we previously mentioned, when offering commercial credits to their client- companies, the suppliers are in the possession of some assets in the form of claims; in turn, such claims are main generators of costs. As long as the supplier is the one deciding whether to offer or not the commercial credit to his client company, he must first and foremost, take into account and estimate both the its efficiency and the benefits implied. To put it differently, before taking such decision, the supplier is bound to compare the benefits with the costs implied.

Claims efficiency may be regarded from various perspectives, namely:

- profits generated by benefits and profit resulted from sales, if hypothetically compared the situation in which the product range counter value would be paid cash;

- advertising efforts economy if we compare it hypothetically with the case in which the same sales volume would be obtained by means of increased advertising efforts;

- production expenses economy if hypothetically compared to situation in which the same sales value would be the result of products quality improvement;

- profit resulted at price level if hypothetically compared to the case in which the same sales volume would be obtained by means of price;

- not offered discounts, if hypothetically compared to the situation we would resort to a cash payment.

Obviously, the profits resulted from this commercial credit system are to be estimated only by taking into account the risks involved. Among these risks, it is worth mentioning, all risks related to the system of paying the client. In conclusion, it is vital for every supplier to be aware of the company possibility of paying its current debts, so that they can take the best decision.

C) The importance of estimating the company's possibilities of paying its debts towards banks or any financial institution

Specific indicators used in evaluating the company's business and credit worthiness represent the basis of any bank analysis evaluating credit worthiness. The main reason is that the client company incapacity risk represents one of the most important risks that taken by the bank when deciding to enter into credit relationships with a certain company.

Despite of the fact that bank credits are usually guaranteed by the company under various forms, may financing institutions take all precaution measure to prevent such risks or the liquidation of the company's warranties. The occurrence of such situation may create inadequacies related to the bank cash flow statement, or it may determine expanses resulted from warranties liquidation (whether such warranties ca or cannot be covered or from finding and penalizing debtor clients.

One of the most common effects which banks usually confront with is that of creating provisions for debtor clients. According to the central bank norms, provisions increase is directly determined and influence by the number of days the client delays with the payment for the services provided.

Despite of the fact that provisions do not have monetary features, these provisions may have an affect negatively the bank financial situation. Although these negative effects differ considerably from the risks regarding non-rectifying principles, rates or commissions:

a) Reduction of the present exercise profit with negative impact not only on the payment possibilities of shareholders (Reduction of dividend distribution possibilities even in cases when the possibilities are real), but also on its own capital structure ( a possible cancellation of provisions without losses would result into a considerable profit increase), which delays the remuneration of shareholders. Moreover, time may determine a decrease in payment value. 
b) A possible capital decrease may reduce the possibility of giving credits and may also diminish the efficiency in operating the funds invested by shareholders (diminishing thus, the shareholders economic investment).

The profit obtained by the bank is directly conditioned by the volume of credits granted. In case the credit risk provisions diminish the proper capital, they may also decrease the bank possibility of granting credits to the same investment made by shareholders either in case of social capital or profit, which the bank can dispose of in any form.

c) Reduction of bank liquidity

Central bank may impose to commercial banks dead lines as regards their capacity of carrying out the present liabilities they have been in charged with. Central banks usually use "liquidation indices" in determining the commercial banks capacity of carrying out the present liabilities they have been in charged with. In essence these liquidation indices compare the present assets to the present liabilities, which have been classified according to the liquidation levels, more precisely, according to exigibility. The present assets value is calculate by using the same method as in the case of capital value. Consequently, rate or credit risk provisions may lead to the liquidation indicators decrease. (by diminishing the capital value of present). In order to maintain the normal values, the bank is bound to take some correction measures which may concern:

- Increase of the existing net assets;

- Reduction of existing / present liabilities.

The efficiency of such measures is conditioned by their application in case of increase of financing sources or determined or undetermined period ( by increasing the costs). Such financing sources shall be used in stead of other sources with higher exigibility (meaning, cheaper) or shall be used to finance assets with increased chances of liquidation (less profitable).

In case the bank's possibility of paying the company is of a major importance for the quasi totality of interest groups, we consider that by using the cash flow statement as method of evaluation seems the best solution. To put into practice such approach would firstly mean to make difficult the job of internal auditor, especially because the it's very difficult to obtain the information necessary for building the cash flow system (either post factum or as a precaution measure).

As regards the cash flow statement, the existing standards have been realized by resorting to all book keeping norms into force: IAS 7, FRS 1, FAS 95.

In the context of globalization phenomenon manifestation, a harmonization process of these standardizations takes place.

We didn't focus on differences regarding the methods of cash flow statement building. Our intention was rather to point out the main features of methods used in creating such cash flow statements. result into:

Consequently, cash flow ins and outs have been classified in 3 activity categories which

- $\quad$ Cash flow resulting from operational activities;

- $\quad$ Cash flow resulting from investment activities;

- $\quad$ Cash flow resulting from financial activities.

By classifying the cash flow according to specific activities the interested groups would benefit of an important informational source. The capital cash flow may be Post-factum, the net cash flux may be determined by comparing asset treasury level between the beginning and the end of the target period. Its value, unaccompanied by other information, does not decisively support the evaluation efforts of future enterprise payment capacity (knowledge of cash flows susceptible to repetition in the future being necessary in this context).

Cash flow from exploitation may be calculated and presented based on 2 general methods: the direct method and the indirect method. The choice between the 2 methods has a significant impact on transmitted information. 
We consider that using the direct method ensures a significant addition of information needed to evaluate enterprise payment capacity. However, applying this method is difficult, due to commitment accountancy uniqueness.

Under these conditions, the indirect method is mainly used, which partially sacrifices the informational inflow regarding cash circulation and cash equivalents. In any case, the indirect method supports the understanding of net result forming method, and also the correlations between changes in the accountancy balance and flow sizes from the profit and loss account.

Ever more, cash flow is used in enterprise financial result evaluation, in the disadvantage of some indicators, specific to the profit and loss account (established in the classic analysis of enterprise performance). The verification of this statement is ensured by the large scale use of methods based on updating and capitalizing cash flow, in terms of value assessment. Thus, the enterprise's market value is more and more linked to its capacity to generate positive cash flows at exploitation level, profit being considered as an insufficient condition.

The priority of cash flows before profit is supported by at least 2 factors in the analysis of enterprise results:

- cash flow is rather difficult to handle from the point of view of accountancy, the provided information being thus clearer;

- regardless of obtained profit size, an enterprise which does not generate sufficient cash, presents at least long term unfavourable perspectives.

Amongst short term profit rebuild possibilities, the following can be noted:

- the setting, in a convenient manner, of write-off policy parameters;

- provision policy;

- policy in terms commercial credit.

In this context, the use of cash flow in comparing enterprise performance is much more desirable. However, taking into consideration eventual differences at the construction of cash flow states is imposed, but also the fact that cash flow size may itself be rebuilt (although possibilities are even more reduced).

Considering the fact that the uniqueness of the Romanian accountancy system (otherwise commitment accountancy in general) makes cash flow construction rather difficult, we propose a construction model, tested and elaborated by the authors, which is exclusively founded on the information offered by the verification balance.

Table no. 1

Cash flow situation construction model, proposed by the authors

\begin{tabular}{|c|l|}
\hline I. & OPERATIONAL ACTIVITIES \\
\hline A. & Total cash sources (A0+A9-A10+A11-A12) \\
\hline A0 & $\begin{array}{l}\text { Operational result before write-off and provisions and extraordinary activities } \\
\text { (A1-A2+A3-A4+A5+A6-A7-A8) }\end{array}$ \\
\hline A1 & Operational result (Profit \& Loss Account) \\
\hline A2 & Other operational incomes (rc [7583+7584]) \\
\hline A3 & Expenses related to transferred assets and other capital operations (line 6853) \\
\hline A4 & Incomes from provisions + line.280,281 (rc [ 7812+ 7813+7814]) \\
\hline A5 & Operational expenses related to write-offs and provisions (line [6811+6812+6813+6814]) \\
\hline A6 & Financial incomes (excepting incomes related to financial investments) (rc [765+766+767+768]) \\
\hline A7 & Financial expenses (excepting expenses related to interests and financial investments) (line [665+667+668]) \\
\hline A8 & Income/ Profit tax expenses (line[691+694]) \\
\hline A9 & Deviation of advance income (rc 472-rd472) \\
\hline A10 & Deviation of advance expenses (line 471-rc471) \\
\hline A11 & Extraordinary income (rc 771) \\
\hline A12 & Extraordinary expenses (line 671) \\
\hline
\end{tabular}




\begin{tabular}{|c|c|}
\hline B. & Total cash operations, our of which (B0) \\
\hline $\mathrm{B} 0$ & Variation of necessary circulation fund, out of which (B1+B2-B3) \\
\hline B1 & $\begin{array}{l}\text { - Stock variation (line - } \\
\text { rc }[301+302+303+331+332+341+345+346+351+354+356+357+358+361+371+381+4091+308+348+368+378+388])\end{array}$ \\
\hline $\mathrm{B} 2$ & - Receivables variation (line-rc[4092+411+413+418+425+4282+4382+4424+445+4482+4582+461+5187)] \\
\hline $\mathrm{B} 3$ & $\begin{array}{l}\text { - Variation of non-financial debts } \\
\text { rc_line[269+401+403+404+405+408+419+421+423+424+426+427+4281+431+437+4381+441+4423+4428+444+446+447+4481+451+45 } \\
2+456+457+4581+462+473+509])\end{array}$ \\
\hline C. & Cash flow resulted from operational activities FNE (A - B) \\
\hline II. & FINANCING ACTIVITY \\
\hline D. & Total cash sources $(\mathrm{D} 1+\mathrm{D} 2+\mathrm{D} 3)$, out of which: \\
\hline D1 & Capital raises, out of which: \\
\hline & - registered capital (rc101) \\
\hline & - increment of capital bonuses (rc. 104); \\
\hline & - increment of re-evaluation reserves (rc.105); \\
\hline & - increment of reserves (rc. 106); \\
\hline & - increment of other own capital elements ([balance]117a-121p-117p+129p) \\
\hline D2 & Raise of the medium and long term financial debts (rc[162+166+167+168+455]) \\
\hline D3 & Raise of the short term financial debts $(\mathrm{rc}[5186+519])$ \\
\hline E. & Total cash operations (E1+E2+E3+E4), out of which: \\
\hline E1 & Capital reductions, out of which: \\
\hline & - registered capital redraws (line 101) \\
\hline & - reductions of capital bonuses (line 104); \\
\hline & - reduction of re-evaluation reserves (line 105); \\
\hline & - reduction of reserves (line 106); \\
\hline & - reduction of other own capital elements ([balance]117a-121p-117p+129p) \\
\hline & - profit distribution (line 129) \\
\hline E2 & Reimbursement of medium and long term financial debts (line $[162+166+167+168+455])$ \\
\hline E3 & Reimbursement of the short term financial debts (line [5186+519]) \\
\hline E4 & Financial expenses related to interests (line 666) \\
\hline F. & Cash flux from the financing activity FNF (D - E) \\
\hline III. & FINANCING ACTIVITY \\
\hline G. & Total cash sources $(\mathrm{G} 1+\mathrm{G} 2+\mathrm{G} 3+\mathrm{G} 4+\mathrm{G} 5)$, out of which: \\
\hline G1 & Incomes from assets sale and other capital operations (rc 7583) \\
\hline G2 & Incomes from investment subventions (rc7584) \\
\hline G3 & Financial incomes related to financial investments $(\mathrm{rc}[761+762+763+764])$ \\
\hline G4 & Gross immobilizations reductions (rc $[201+203+205+207+208+233+234+211+212+213+214+231+232+261+262+263+265+267])$ \\
\hline G5 & Raise of investment subventions (rc. 131) \\
\hline H. & Total cash operations $(\mathrm{H} 1+\mathrm{H} 2+\mathrm{H} 3+\mathrm{H} 4)$, out of which: \\
\hline $\mathrm{H} 1$ & Expenses related to transferred assets and other capital operations (line 6583) \\
\hline $\mathrm{H} 2$ & Financial expenses related to financial investments (line[663+664]) \\
\hline $\mathrm{H} 3$ & $\begin{array}{l}\text { Increase of gross immobilizations } \\
\text { (line }[201+203+205+207+208+233+234+211+212+213+214+231+232+261+262+263+265+267])\end{array}$ \\
\hline $\mathrm{H} 4$ & Reduction of investment subventions (line 131) \\
\hline I. & Cash flow from investment activities FNI (G - H) \\
\hline J. & Total cash flow of the period $(C+F+I+L)$ \\
\hline K. & $\begin{array}{l}\text { Cash availabilities at the beginning of the period } \\
(\operatorname{Sd}[5112+5121+5124+5125+531+532+541+542+581+501+502+503+505+506+508+5113+5114])\end{array}$ \\
\hline L. & Cash avalilabilities at the end of the period (+exceeding /-deficit) $(M+N)$ : \\
\hline
\end{tabular}




\section{References:}

1. Checkley Keith, Cash is king, Pitman Publishing, London, 1994;

2. Ciobanu Anamaria, Analiza performantei intreprinderii, Editura ASE, Bucuresti, 2006;

3. Dragota Victor, Abordari practice in finantele firmei, Editura Irecson, Bucuresti, 2005;

4. Halpern Paul, Finante manageriale, Editura Economica, Bucuresti, 1998;

5. Stancu Ion, Finante, Editura Economica, Bucuresti, 1997;

6. Ward Keith, Corporate financial strategy, Bath Press, Bath, 2001. 